\title{
Radiographic Assessment of the Change in the Maxillarysinus Mucosa in Proximity to Periodontally Involved Teeth
}

\author{
Tihomir Georgiev $^{1}$, Krasimira Prodanova ${ }^{2}$, Georgi Papanchev ${ }^{3}$ \\ ${ }^{1,3}$ Department of Oral and Maxillofacial Surgery, Faculty of Dental Medicine, Medical University of Varna \\ ${ }^{2}$ Department of Stochastic\&Optimization, Technical University of Sofia
}

\begin{abstract}
The aim of the present study is to explore the correlation between maxillary sinus diseases and inflammatory processes in the maxillary teeth in patients eligible for implant rehabilitation with a preoperative examination using cone-beam computed tomography (CBCT).Materials and methods:282 CBCT images of the maxilla and 530 images of the maxillary sinus were analyzed. Only teeth with chronic periodontitis and with no other pathological process were recruited in the target group.The distance between the sinus floor and theperiodontal pocketdepth(PPD) and the thickness of theSchneiderian membranearound each tooth was recorded.Results: The mean thickness of the maxillary sinus mucosawas $7.74 \mathrm{~mm}$, reaching its highest value at 26 mm (as seen in 2 patients with chronic periodontitis). The mean distance between the periodontal involvement and the maxillary sinus floor for the affected teeth was 5.53 mm. The distance varied between $0 \mathrm{~mm}$ and $13 \mathrm{~mm}$.Conclusions: This retrospective study showed that the thickness of the sinus membrane is directly related to the inflammatory processes of periodontium of the teeth adjacent to the sinus.
\end{abstract}

Keywords: maxillary sinus, mucosal thickening, periodontal bone loss

\section{Introduction}

The inflammatory deseases of maxillary teeth may ascend to the maxillary sinus and subsequently induce various pathological responses.[1,2]Periodontitis is regarded as the second most common cause oftooth loss resulting from the loss of the tooth-supporting apparatus. [3] Datareported in previous studiessuggest that $10-12 \%$ of maxillary sinusitis have an odontogenic origin. [4] The most common causes of odontogenic sinusitis are periapical and periodontal inflammatory processes leading to changes in the normal anatomy of the sinus membrane. [5] Other studies have shown a relationship between periodontitis and periapical lesions and MT [6,7], particularly occurringin cases where root apexes of distal maxillary teeth protrude into the maxillary sinus. [8] Cone-beam computed tomography has more advantages over conventional radiographic techniques for recognition of the relationship betweentooth pathologyand the maxillary sinus. $[9,10]$

\section{Materials and Methods}

The images for the present study were acquired with a conebeam computed tomographyscanner (PlanmecaProMax 3D Max), integrated with a computer hard drive and backup peripheral devices, software for reconstructing images (PlanmecaRomexis) and apatients registration program. Scanning parameters wereas follows: scanning time 9-40 sec., imagereconstruction time 2-55 sec. CBCT images were stored and read by PlanmecaRomexis Software, compatible with Windows XP, Windows 7 and Windows 8. A total of 435 images of the maxilla were reviewed,the inclusion criterion being those images which displayed present teeth under the maxillary sinuses, namely canines, premolars and molars. Following radiographic examination, the study excluded 153 images where patients had distal maxillary edentulism. The target group involved $282 \mathrm{CBCT}$ images of
530 sinuses and 1202 teeth withpatients' age varing from 16 to 82 years. Out of those images, we selected the teeth that had lost their supporting apparatus, exhibiting no other pathology (Figure 1a and 1b). Measurements were taken of the distance between the pathological process and the maxillary sinus as well as the thickness of the Schneiderianmembraneabove these teeth (Figure2)
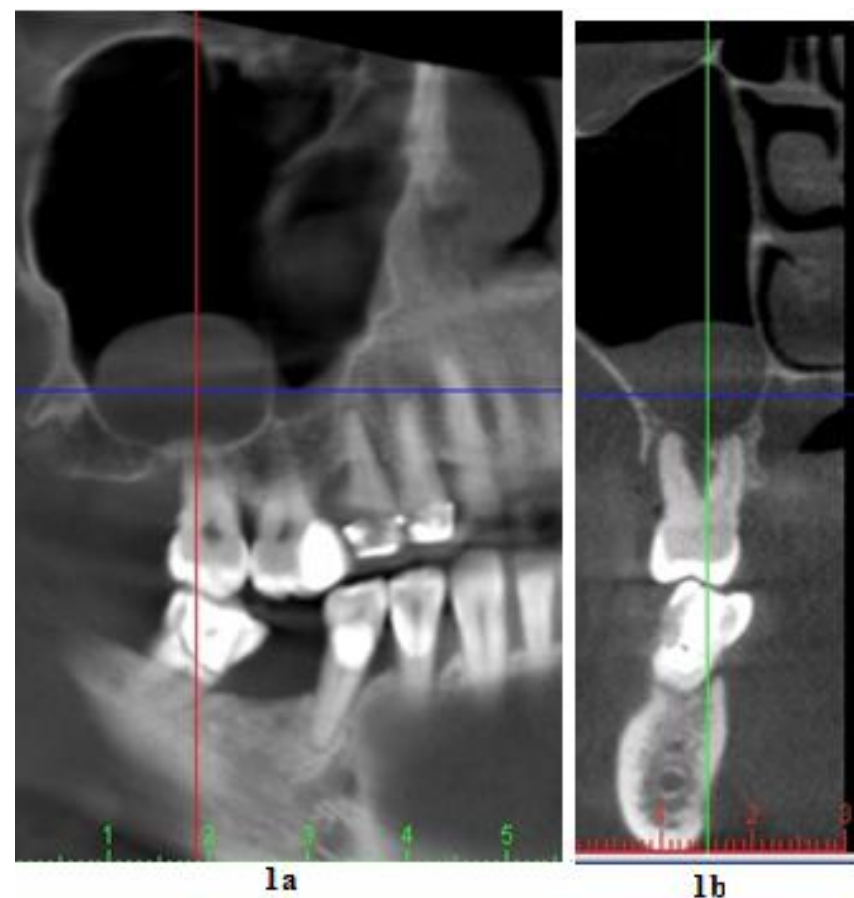

Figure 1a and 1b.Teeth with periodontal bone loss and mucosal thickining of the maxillary sinus 


\section{International Journal of Science and Research (IJSR) \\ ISSN (Online): 2319-7064}

Index Copernicus Value (2013): 6.14 | Impact Factor (2015): 6.391

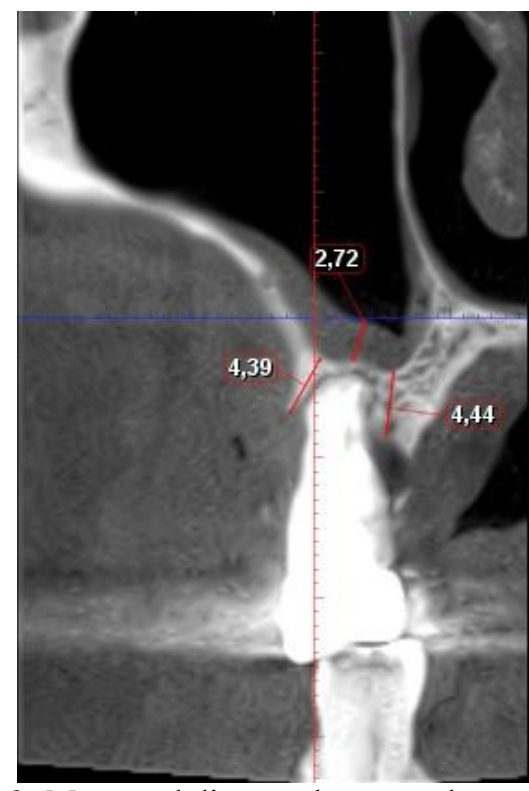

Figure 2: Measured distance between the periodontal pocketdepthand the sinus floor and the mucosal thickness of the maxillary sinus
Measurements were taken by two lecturers at the University Medical Dental Clinic, performed independently, evaluating the thickness of the sinus membrane as well as the distance between the inflammatory process in the periodontium and the sinus floor. The statistical hypotheses concerning differences of two means were tested using t-test for paired samples with a level of significance of 0,05 .

Any discrepancies in the parameters under study were consulted with a dental radiologist.

\section{Results}

282 CBCT images of the maxilla were analyzed, comprising 530 maxillary sinuses with 1202 contiguous present teeth, of which 256 teeth had lost their supporting apparatus. The study excluded teeth with more than one etiological entity of inflammation, i.e. periodontitis and periapical cyst. 100 teeth met our criteria, displaying only one nosological entity, i.e. periodontitis, whereas 97 teeth showed changes in the maxillary sinus mucosa, i.e. thickening of the membrane over $2 \mathrm{~mm}$, retention cysts or pseudocysts. (Fig.3)

Sinus mucosal thickening (MT) was considered to be when there was a visible thickness of $\geq 2 \mathrm{~mm}$.

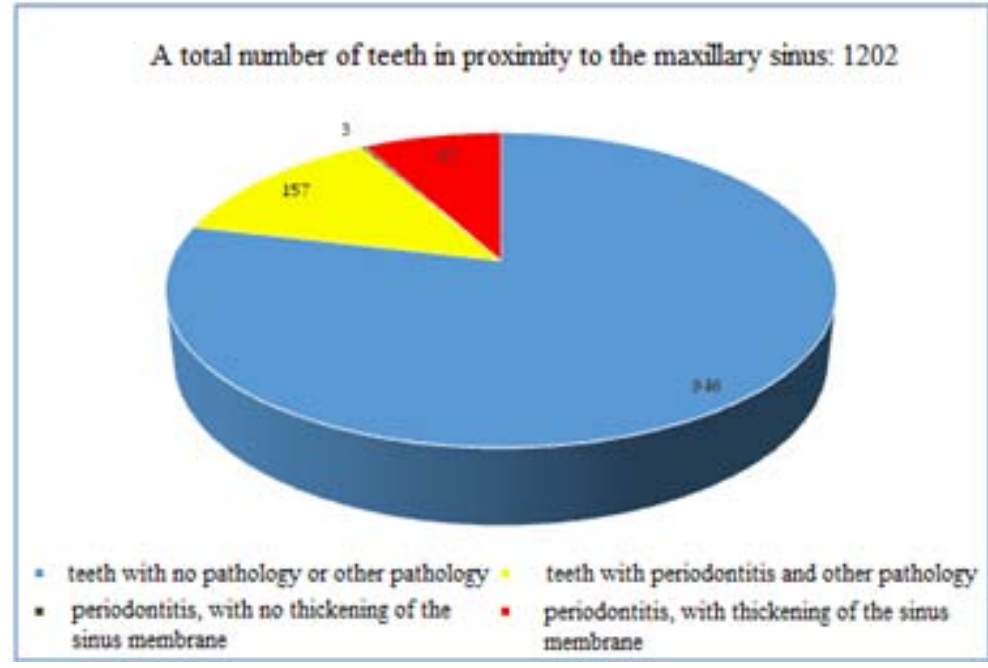

Figure 3: Distribution of the number of teeth involved in a pathological process in proximity to the maxillary sinus

The mean thickness of the sinus membrane in proximity topresent teethwas $7.74 \mathrm{~mm}$, showing signs of contiguousbone and tissue loss. At its thickest the membrane was measured $26 \mathrm{~mm}$, taken in2 patients with chronic periodontitis.
The mean distance between the periodontal involvement and the maxillary sinus floor for the affected teeth was $5.53 \mathrm{~mm}$. The distance varied between $0 \mathrm{~mm}$ and $13 \mathrm{~mm}$. (Table 1)

Table 1: Statistical characteristics ofmucosal thickening (MT) and periodontal bone loss (PBL)

\begin{tabular}{|c|c|c|c|c|c|c|c|}
\hline \multicolumn{8}{|c|}{ Descriptive Statistics } \\
\hline & \multirow[t]{2}{*}{ Valid N } & Mean & \multirow{2}{*}{$\begin{array}{c}\text { Confidence } \\
-95,000 \%\end{array}$} & \multirow{2}{*}{$\begin{array}{l}\text { Confidence } \\
+95,000 \%\end{array}$} & \multirow[t]{2}{*}{ Min } & \multirow[t]{2}{*}{ Max } & \multirow[t]{2}{*}{ Std.Dev. } \\
\hline & & $(\mathrm{mm})$ & & & & & \\
\hline MT & 97 & 7,74 & 6,58 & $8,899,981$ & 0,00 & 26,00 & 5,75 \\
\hline PBL & 97 & 5,53 & 4,91 & $6,142,253$ & 0,00 & 13,00 & 3,06 \\
\hline
\end{tabular}




\section{International Journal of Science and Research (IJSR) \\ ISSN (Online): 2319-7064}

Index Copernicus Value (2013): 6.14 | Impact Factor (2015): 6.391

Table 2: shows the frequency distribution of the distance measured between the PBL and the sinus floor for the 97 teeth with mucosal thickening (MT) of the maxillary sinus

\begin{tabular}{|c|c|c|c|}
\hline \multicolumn{3}{|c|}{ Frequency table: period ontal bone loss (PBL) } \\
\hline PBL $(\mathrm{mm})$ & Count & $\begin{array}{c}\text { \% of A.11 } \\
\text {-Cases }\end{array}$ & $\begin{array}{c}\text { Cum ulative \% - of } \\
\text { A.11 }\end{array}$ \\
\hline 0,00 & 2 & 2,06186 & 2,0619 \\
\hline$(0-2]$ & 21 & 21,64948 & 23,7113 \\
\hline$(2-4]$ & 14 & 14,43299 & 38,1443 \\
\hline$(4-6]$ & 16 & 16,49485 & 54,6392 \\
\hline$(6-8]$ & 28 & 28,86598 & 83,5052 \\
\hline$(8--10]$ & 12 & 12,37113 & 95,8763 \\
\hline$(10-12]$ & 3 & 3,09278 & 98,9691 \\
\hline$(12-14]$ & 1 & 1,03093 & 100,0000 \\
\hline A.11 & 97 & & 100,0000 \\
\hline
\end{tabular}

The histogram reflecting this frequency distribution is shown in Figure 4.

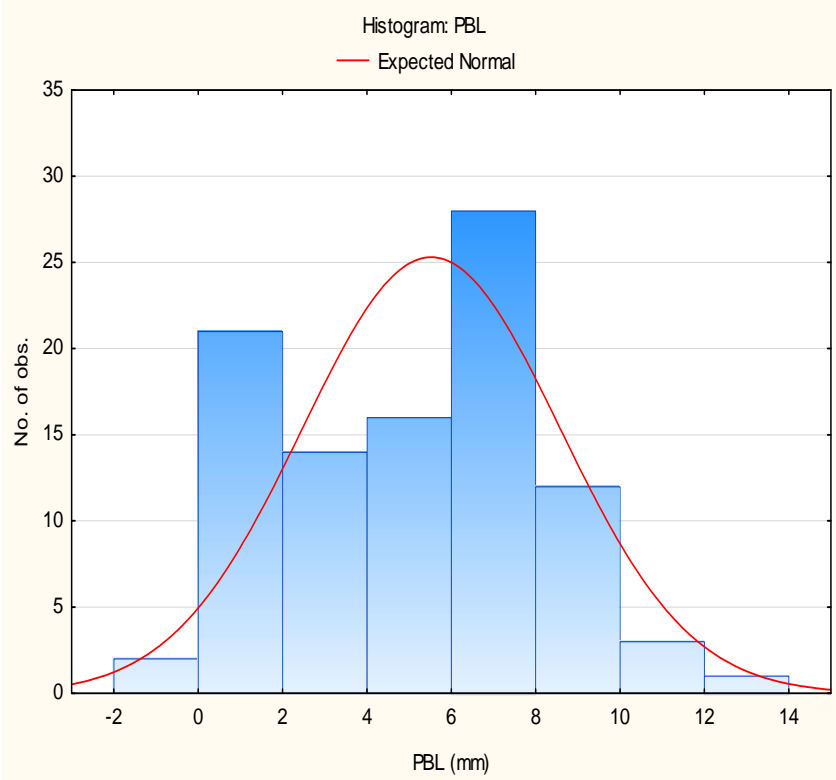

Figure 4: Histogram of periodontal bone loss (PBL)

Table 3 displays the frequency distribution of the PBLfor the97teeth with mucosal thickening (MT) of the maxillary sinus.
Table 3: Frequency distribution of membrane thickening (MT) of the maxillary sinus

\begin{tabular}{|c|c|c|c|}
\hline \multicolumn{2}{|c|}{ Frequency table: membrane or mucosal thickening } \\
\hline MT (mm) & Count & $\begin{array}{r}\text { \% of A11 } \\
\text { - Cases }\end{array}$ & $\begin{array}{c}\text { Cumvlative \% } \\
\text { - of All }\end{array}$ \\
\hline 0,00 & 1 & 1,03093 & 1,0309 \\
\hline$(0-5\}$ & 46 & 47,42268 & 48,4536 \\
\hline$(5-10]$ & 22 & 22,68041 & 71,1340 \\
\hline$(10-15]$ & 19 & 19,58763 & 90,7216 \\
\hline$(15-20]$ & 5 & 5,15464 & 95,8763 \\
\hline$(20-25]$ & 2 & 2,06186 & 97,9381 \\
\hline$(25-30]$ & 2 & 2,06186 & 100,0000 \\
\hline A11 & 97 & & 100,0000 \\
\hline
\end{tabular}

The histogram reflecting this frequency distribution is shown in Figure 5.

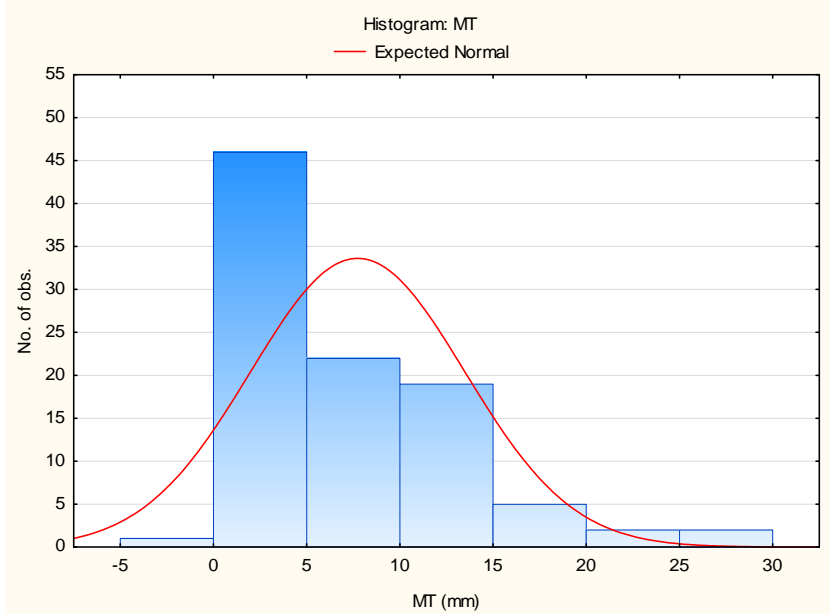

Figure 5: Histogram of the membrane thickening (MT) of the maxillary sinus

Themost common changes in the maxillary sinus membrane involved its thickening in $87 \%$ of the cases, mucocelein $7 \%$ of the cases and pseudocysts $-6 \%$.

As the first step, we used linear regression model [17] to investigate the relationship between PBL and MT. (Figure 6) 


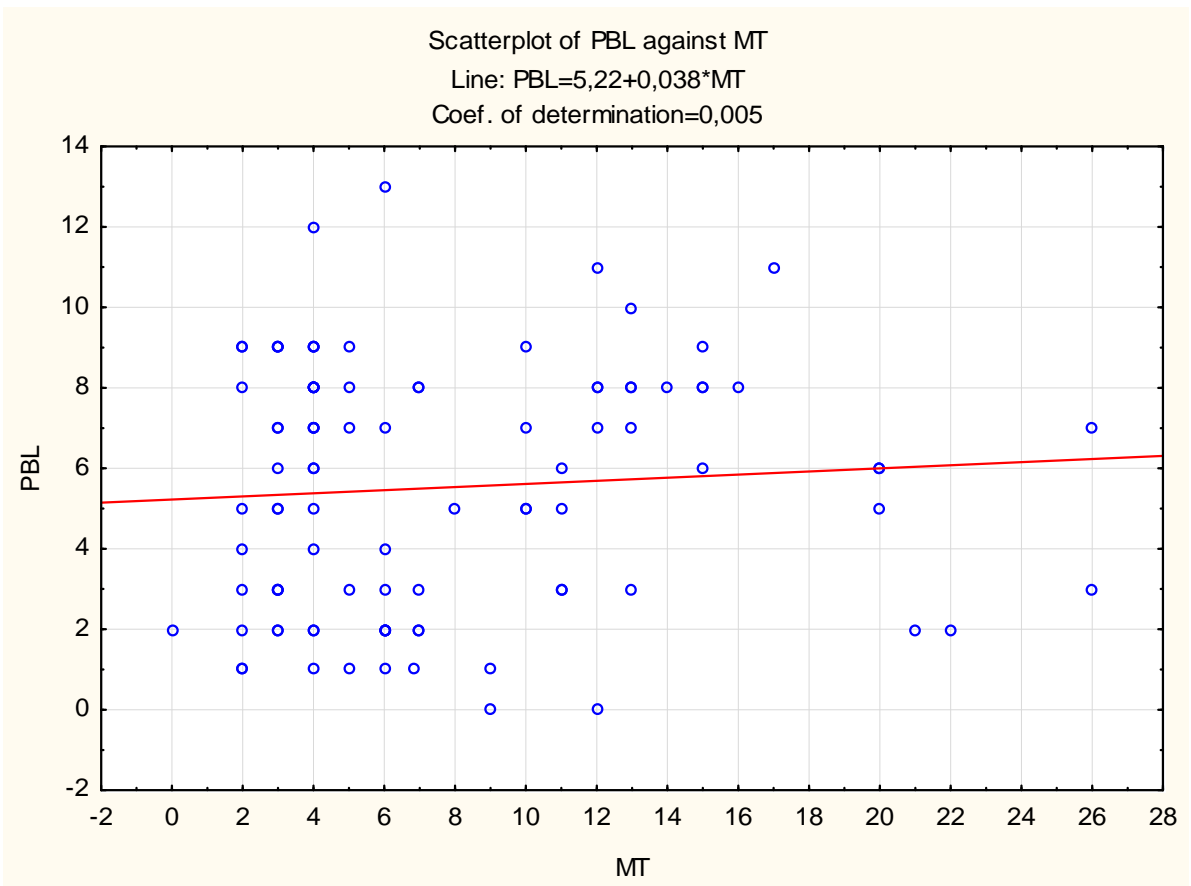

Figure 6: Scatterplot of PBL against MT

The square value of the correlation coefficient (coefficient of determination) for this model was 0.005 , which showed that the values of MT were only in $0,5 \%$ determined by the values ofPBL.

The shape of the points on the scatter plot gave us reason to use the analysis method of variance [17] to establish the relationship between PBL and MT. The Analysis of variance (ANOVA) is a statistical technique for analyzing observation (in our case for PBL) that depends on the effects of one or more (in our case one - MT) factor. Our factor occurred at 27 groups (levels) of MT (from $0 \mathrm{~mm}$ to 26 $\mathrm{mm}$ ). The verification procedure was based on the assumption that the significance of the difference between means may be evaluated upon the share of the variation between groups in the overall variation of the response variable PBL. The procedure applied was to decompose the overall variation into two parts: measuring the variation between groups and within groups, and afterwards to evaluate their contribution to overall differentiation of the response variable PBL (Figure 7).

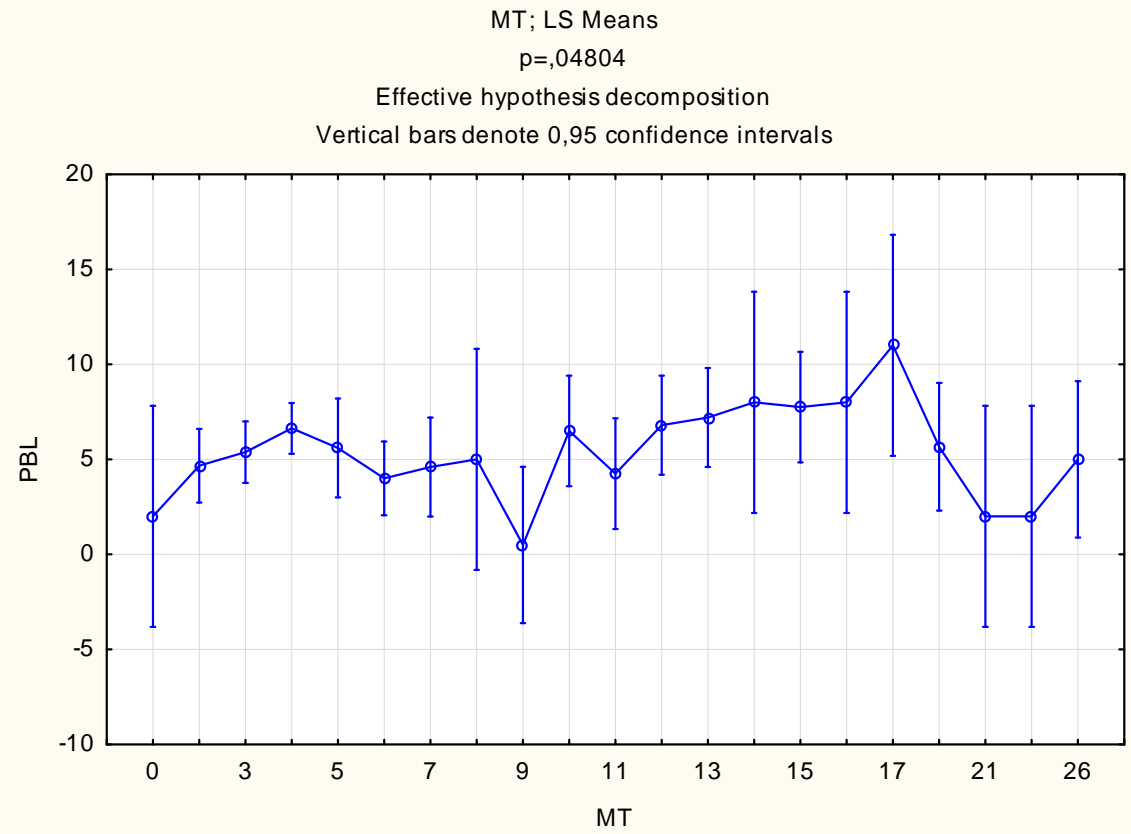

Figure 7: Decomposition of the overall variation in MT using variation between groups and within groups ofPBL.

Analysis of data using ANOVAin the statistical package STATISTICA[16]represented that the levels of PBL influenced the value of the mucosal thickeningof the maxillary sinus $(\mathrm{p}=0,04804<0,05)$. (Table 4$)$ 
International Journal of Science and Research (IJSR)

ISSN (Online): 2319-7064

Index Copernicus Value (2013): 6.14 | Impact Factor (2015): 6.391

Table 4: Analysis of variance table

\begin{tabular}{|c|c|c|c|c|c|}
\hline \multicolumn{5}{|c|}{ Univariate ANOVA Test } \\
\hline & SS & $\begin{array}{c}\text { Degr. of } \\
\text { Freedom }\end{array}$ & MS & $F$ & $P$ \\
\hline Intercept & 1237,641 & 1 & 1237,641 & 145,2257 & 0,00001 \\
\hline Factor (membrane or mucosal thickering & 238,325 & 20 & 11,916 & 1,3983 & 0,04804 \\
\hline Random effect (Error tem) & 639,165 & 75 & 8,522 & & \\
\hline
\end{tabular}

The univariate analysis of varianceconducted for the purpose of this study demonstrated statistically significant correlation between the distance between the inflamed periodontium of the affected toothand the MT of the maxillary sinus.

\section{Discussion}

Moskow BS [11]showed the relationship between periodontal inflammation and pathological processes in the maxillary sinus. Heused 20 block sections of human jaws obtained at autopsy, containing maxillary molar teeth with the contiguous maxillarysinus intact. He studied them by light microscopy, utilizing conventional histopathologic techniques.17 of 20 jaw specimens demonstrated moderate to advanced periodontal destruction with pervasive extension through the alveolar ridge to the maxillary sinus antrum. 10 of the specimens showed extensive thickening of the sinus membrane, while 9 had hyperplastic changes, and only 1 specimen demonstrated a normal appearing mucosal thickness (MT).Pathological changes in the sinus membrane included inflammatory cell infiltration, edema, fibrosis of the tunica propria, mucous-serous gland proliferation, interstitial pseudo-cyst formation, polyp formation, hyalinization of the connective tissue lining, thrombosis of blood vessels, and metaplastic and degenerative changes in the epithelial lining.

Ren $\mathrm{S}$ et al. [12] characterized theSchneiderian membranein patients with periodontal disease of maxillary teeth, using 3D images. 221 patients were subjected to cross-sectional CBCT examination where various parameters, including age, sex, alveolar bone loss, furcation lesions and vertical infrabony pockets, were analysed in correlation with any mucosal thickening (MT). MT was detected in 103 patients $(48.9 \%)$, increasing in frequency as the degree of alveolar bone loss advanced.The association between vertical infrabony pockets, furcation lesionsand thickening of the Schneiderian membranewas statistically significant $(\mathrm{P}<$ 0.001).

Sheikhi $\mathrm{M}$ et al. [13] performed a similar study with conebeam computed tomography, searching for a link between periodontal bone loss and inflammatory response in the sinus membrane. A total of 180 CBCT images were reviewed. Periodontal bone loss (PBL) was assessed in six points under each sinus at the mesial and distal sides of the upper second premolar and first and second molars by measuring the distance from the alveolar crest to the point 2 $\mathrm{mm}$ under the cemento-enamel junction (CEJ). The MT was assessed at six points in the floor of the sinus precisely over the mentioned points.Change in MT was observed in 39.4\% of patients $($ mean $=4.68 \pm 5.25 \mathrm{~mm})$. Linear regression test showed that there is an association between PBL of maxillary teeth and MT.
Phothikhun S et al. [4)]carried out $250 \mathrm{CBCT}$ scans of dental patientsto determine the relationship between periodontal inflammatory diseases and any abnormalities of the Schneiderian membrane:the presence of mucosal thickening and mucosal retention cysts. The following dental findings were recorded: mucosal thickening was present in $42 \%$ of patients and in $29.2 \%$ of sinuses studied. Mucosal cysts were observed in $16.4 \%$ of patients and in $10 \%$ of sinuses studied.Mucosal cysts were observed in $16.4 \%$ of patients and in $10 \%$ of sinuses studied. Severe periodontal bone loss for maxillary teeth was significantly associated with mucosal thickening and the contiguous maxillary sinuses were three times more likely to have mucosal thickening. Mucosal cysts were not associated with any dental findings.

Goller-Bulut D et al. [14]made a retrospective analysis of CBCT images of 205 patients with 410 maxillary sinus, measuring periodontal bone loss (PBL)of 582 maxillary molars and 587 premolars, in order to identify the associationbetween mucosal thickness and periapical condition of related teeth. They found a positive correlation between mucosal thickness (MT) of the maxillary sinusand PBL and the age of patients (increasing MT as the age advanced).

Roque-Torres GD et al. [5]alsoevaluated the relationship between the proximity of the roots ofdistal maxillary teeth, the loss of periodontal alveolar bone and the inflammatory response in the maxillary membrane by more than $2 \mathrm{~mm}$.

For the purposes of the present study, the authors examined only selected teeth $(n=99)$, affected by periodontal disease with bone loss of more than $2 \mathrm{~mm}$ in proximity to the maxillary sinuses. The findings accounted for the conclusions that the change in MT could only be the result of a periodontal inflammatory process. For all teeth under study, the observations revealed that the apexes of those teeth were either in close proximity to the sinus $(2 \mathrm{~mm})$ or there was communication between them. This explained the high percentage $(96.99 \%, 96$ teeth out of 99 studied) of response of the maxillary sinus in our study compared to the above-mentioned publications. Another reason for the high percentage can be related to the fact that we utilized CBCT scans of patients with planned implant treatment due to tooth loss or pending tooth extraction in the distal regions, so we encountered a large amount of advanced and marked bone loss.

The mean thickness of the sinus membrane in the present study was $7.82 \mathrm{~mm}$ and in most cases there was a lack of complaints associated with the maxillary sinus. The patients with thickened Schneiderian membraneof over $20 \mathrm{~mm}(\mathrm{n}=6)$ 


\section{International Journal of Science and Research (IJSR) \\ ISSN (Online): 2319-7064}

Index Copernicus Value (2013): 6.14 | Impact Factor (2015): 6.391

had a history of complaints associated with nasal congestion, sinus pressure and intermittent dull discomfort.

Correlation in the distance of the periodontal pocketdepthto the sinus floor and the thickness of the sinus membrane was not established.

\section{Conclusions}

The loss of the tooth-supporting apparatus due to an inflammatory process in distal maxillary teeth has an impact on the status of the maxillary sinus, the most common pathology being the thickening of the Schneiderian membrane. CBCT is an essential diagnostic tool in the search for an association between various maxillary organs and structures.

\section{References}

[1] Vallo J, Suominen-Taipale L, Huumonen S, Soikkonen K, Norblad A. Prevalence of mucosal abnormalities of the maxillary sinus and their relationship to dental disease in panoramic radiography: Results from the health 2000 health examination survey. Oral Surg Oral Med Oral Pathol Oral Radiol Endod. 2010;109:E80-7.

[2] Puglisi S, Privitera S, Maiolino L, Serra A, Garotta M, Blandino $\mathrm{G}$, et al. Bacteriological findings and antimicrobial resistance in odontogenic and nonodontogenic chronic maxillary sinusitis. J Med Microbiol. 2011;60:1353-9

[3] Shao MY, Huang $\mathrm{P}$, Cheng $\mathrm{R}$, Hu T. Interleukin-6 polymorphisms modify the risk of periodontitis: A systematic review and meta-analysis. J Zhejiang Univ Sci B. 2009;10:920-7.

[4] Phothikhun S, Suphanantachat S, Chuenchompoonut V, Nisapakultorn K. Cone-beam computed tomographic evidence of the association between periodontal bone loss and mucosal thickening of the maxillary sinus. J Periodontol. 2012;83:557-64.

[5] Engström H, Chamberlain D, Kiger R, Egelberg J. Radiographic evaluation of the effect of initial periodontal therapy on thickness of the maxillary sinus mucosa. J Periodontol. 1988;59:604-8.

[6] Falk H, Ericson S, Hugoson A. The effects of periodontal treatment on mucous membrane thickening in the maxillary sinus. J Clin Periodontol. 1986;13:21722.

[7] Nenzén B, Welander U. The effect of conservative root canal therapy on local mucosal hyperplasia in the maxillary sinus. Odontol Revy. 1967;18:295-302.

[8] Georgiev T., S.Peev, H.Arnautska Relationship between root apicesof maxillary posterior teeth and the maxillary sinus floor in patientsfrom Varna region. MedInform 2,2015,4:300-309

[9] Mafee MF, Tran BH, Chapa AR. Imaging of rhinosinusitis and its complications: Plain film, CT, and MRI. Clin Rev Allergy Immunol. 2006;30:165-86.

[10] Scarfe WC, Farman AG, Sukovic P. Clinical applications of cone-beam computed tomography in dental practice. J Can Dent Assoc. 2006;72:75-80

[11] Moskow BS. A histomorphologic study of the effects of periodontal inflammation on the maxillary sinus mucosa.J Periodontol. 1992 Aug;63(8):674-81.
[12]Ren S, Zhao H, Liu J, Wang Q, Pan Y. Significance of maxillary sinus mucosal thickening in patients with periodontal disease.Int Dent J. 2015 Dec;65(6):303-10. doi: 10.1111/idj.12186. Epub 2015 Oct 9.

[13] Sheikhi M, Pozve NJ, Khorrami L. Using cone beam computed tomography to detect the relationship between the periodontal bone loss and mucosal thickening of the maxillary sinus.Dent Res J (Isfahan). 2014 Jul;11(4):495-501.

[14] Goller-Bulut D, Sekerci AE, Köse E, Sisman Y. Cone beam computed tomographic analysis of maxillary premolars and molars to detect the relationship between periapical and marginal bone loss and mucosal thickness of maxillary sinus.Med Oral Patol Oral Cir Bucal. 2015 Sep 1;20(5):e572-9.

[15] Roque-Torres GD, Ramirez-Sotelo LR, Vaz SL, de Almeida de Bóscolo SM, Bóscolo FN. Association between maxillary sinus pathologies and healthy teeth.Braz J Otorhinolaryngol. 2016 Jan-Feb;82(1):33-8. doi: 10.1016/j.bjorl.2015.11.004. Epub 2015 Dec 10.

[16] StatSoft, Inc., STATISTICA Manual (Data analysis software system), Version 10.0, 2010.

[17] Jobson, J.D., Multivariate Data Analysis, vol. 2, Springer Ver., 1991; 209-241

\section{Author Profile}

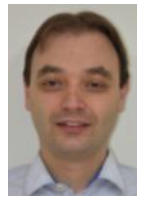

Tihomir Dobrinov Georgiev, DMD, PhD completedhis Master's degree in Dentistry in 1999. Hespecialized in Oral Surgery at the Dental School, MU - Odessa, Ukraine in 2005, as wellas in Health Management at the Medical University - Varna in2011. In 2005 he obtained his $\mathrm{PhD}$ degree in Oral Surgery at the Department of Oral and Maxillo-Facial Surgery, Dental School, MU - Odessa. The topic of PhD thesis is : "Surgical treatment of generalized periodontitis in patients with reduced mineral bone density". Since 2013 he has been Assoc. Prof. and Chief of Oral Surgery at the Department of Oral and Maxillo-Facial Surgery, FDM, MU-Varna. His research interests are in the area of implantology, oral surgery and periodontal surgery. Dr. Georgiev is a member of Bulgarian Association of Oral Implantology(BAOI), ITI, Board of BAOI, ITI Fellow. 